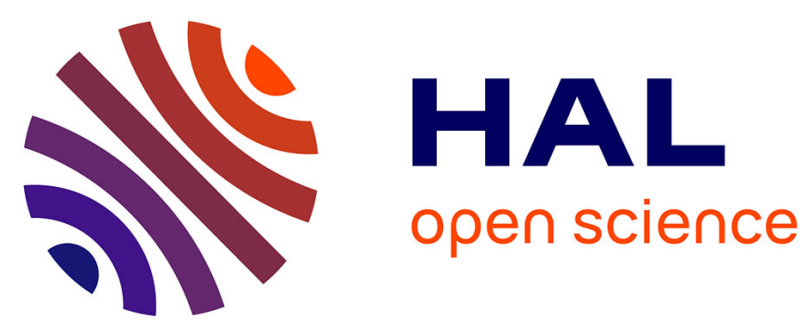

\title{
Anthropometric and behavioral patterns associated with weight maintenance after an obesity treatment in adolescents.
}

\author{
Sandrine Péneau, Hélène Thibault, David Meless, Daniele Soulié, Pierre \\ Carbonel, Daniele Roinsol, Emmanuel Longueville, Patrick Sérog, Michèle \\ Deheeger, France Bellisle, et al.
}

\section{To cite this version:}

Sandrine Péneau, Hélène Thibault, David Meless, Daniele Soulié, Pierre Carbonel, et al.. Anthropometric and behavioral patterns associated with weight maintenance after an obesity treatment in adolescents.: Weight loss maintenance in adolescents. J Pediatr, 2008, 152 (5), pp.678-84. 10.1016/j.jpeds.2007.09.053 . inserm-00173560

\section{HAL Id: inserm-00173560 https://www.hal.inserm.fr/inserm-00173560}

Submitted on 17 Apr 2008

HAL is a multi-disciplinary open access archive for the deposit and dissemination of scientific research documents, whether they are published or not. The documents may come from teaching and research institutions in France or abroad, or from public or private research centers.
L'archive ouverte pluridisciplinaire HAL, est destinée au dépôt et à la diffusion de documents scientifiques de niveau recherche, publiés ou non, émanant des établissements d'enseignement et de recherche français ou étrangers, des laboratoires publics ou privés. 
1 Anthropometric and behavioral patterns associated with weight maintenance after

2 an obesity treatment in adolescents

4 SANDRINE PÉNEAU, DSC, HÉLÈNE THIBAULT, MD, DAVID MELESS, MSC,

5 DANIELE SOULIÉ, MD, PIERRE CARBONEL, MD, DANIELE ROINSOL, RN, 6 EMMANUEL LONGUEVILLE, RD, PATRICK SÉROG, MD, MICHÈLE 7 DEHEEGER, RD, FRANCE BELLISLE, DSC, SYLVIE MAURICE-TISON, MD 8 AND MARIE FRANÇOISE ROLLAND-CACHERA, DSC.

10 From the INSERM, U557, Bobigny, France ; INRA, U1125, Bobigny, France ; CNAM, 11 EA3200, Bobigny, France ; Univ Paris13, Bobigny, France ; CRNH IdF, Unité de 12 Recherche en Epidémiologie Nutritionnelle, Bobigny, F-93017, France (S.P., M.D., 13 F.B., M.F.R.C.); INSERM, U593, Bordeaux, F-33076 France ; Univ Victor Segalen 14 Bordeaux 2, Bordeaux, F-33076 France (H.T., D.M., S.M.T.); Maison Médicale 15 Spécialisée Les Oiseaux, Sanary-sur-Mer, France (D.S., P.C., D.R., E.L., P.S.)

18 Address correspondence to Marie Françoise Rolland-Cachera, UMR 19 Inserm/Inra/Cnam/Univ Paris 13, CRNH Ile-de-France, SMBH Paris 13, 74 rue Marcel 20 Cachin, 93017 Bobigny Cedex, France. E-mail : mf.cachera@uren.smbh.univ-paris 13.fr

22 No conflict of interest.

23 No honorarium, grant or other form of payment given to produce the manuscript.

24 Manuscript first draft written by Sandrine Péneau, DSc. 


\section{ABSTRACT}

28 Objective To identify anthropometric and behavioral characteristics associated with

29 weight maintenance after an obesity treatment.

30 Study design Seventy-two adolescents enrolled in a 9-month obesity treatment were

31 followed 1 and 2 years after discharge. Two equally distributed groups, "successful" vs.

32 "limited or no success", were constituted on the basis of the differences in BMI z-score

33 between inclusion and end of follow-up. Anthropometric and behavioral characteristics

34 were compared between groups.

35 Results Both groups showed a decrease of BMI z-score between inclusion and

36 end of follow-up: $2.09 \pm 0.68$ SD for the successful group and $0.65 \pm 0.43$ SD for the

37 group with limited or no success. Groups did not differ during treatment for any of the

38 anthropometric characteristics considered, while differences clearly appeared 1 year

39 after treatment and generally stabilized during the second year. Later adiposity rebound,

40 trend for lower BMI in the mother, and lower total energy intake, more energy at

41 breakfast, less snacking and television during follow-up were recorded in the successful

42 group.

\section{Conclusions}

44 Weight loss maintenance cannot be predicted neither by anthropometry during

45 treatment nor by behavioral characteristics at inclusion, but can already be estimated

461 year after discharge. Early life factors should also be taken into account for the

47 prediction of treatment outcome. 
49 Key words: obesity; adolescent behavior; body composition; feeding behavior;

50 treatment outcome; sedentary behavior; early determinants.

51

52 ABBREVIATIONS.

53 BMI, body mass index; UFE, upper arm fat area estimate; UME, upper arm muscle area 54 estimate.

55

56 RUNNING HEAD.

57 Weight loss maintenance in adolescents

58

59 WORD COUNTS.

60 - Text excluding abstract, acknowledgments, figure legends, and references: 2951

$61 \quad-\quad$ Abstract: 201

62

63 NUMBER OF FIGURES. $\mathrm{n}=1$

64 NUMBER OF TABLES. $\mathrm{n}=2$

65

66

67

68

69

70 


\section{INTRODUCTION}

73 Obesity is associated with a number of health issues, which can be physical (e.g. 74 hyperlipidemia, hypertension, infertility, cardiovascular and digestive diseases) as well 75 as psychological (e.g. depression, low self-esteem). ${ }^{1,2}$ Moreover, obese children have a

76 higher risk than their counterparts to be obese adults ${ }^{3,4}$ and, to have an increased 77 morbidity and mortality rate independently of their weight as adults. ${ }^{5}$ It is therefore of 78 particular importance to prevent obesity occurrence in children and adolescents.

79 When prevention is not successful, weight loss treatments are considered. These 80 treatments can have varying durations, but they consistently lead to a weight reduction 81 in children and adolescents. ${ }^{6-13}$ Although short term outcomes are encouraging, 82 maintaining weight loss on the long term is often difficult to achieve. Follow-up of 83 children after treatment clearly showed that, while some of them succeeded, a 84 significant number of children could not maintain weight loss within one or two years 85 after the end of treatment. ${ }^{6,12,14,15}$ Although it is difficult to give specific figures on 86 treatment outcome, since they strongly depend on evaluation methods and duration of

87 follow-up, it seems that treatment results are generally not satisfactory. ${ }^{16,17}$ A significant 88 amount of work is therefore required to improve long-term maintenance of pediatric 89 obesity.

90 Among adults, successful long-term weight loss maintainers have been shown to share

91 common behavioral strategies, including eating a diet low in fat, frequent self92 monitoring of body weight and food intakes, and high levels of regular physical 93 activity. ${ }^{18}$ Current data on the characteristics involved in the long-term weight loss 94 maintenance in adolescents are however limited and need to be further investigated. 95 While weight and/or body mass index (BMI) are the main outcome in most studies, 
96 additional anthropometric indicators, which allow a better assessment of body

97 composition and predict associated risk factors, should be included. ${ }^{19}$

98 We previously reported the influence of 9 month weight-reducing diets containing

99 different amounts of protein and $\mathrm{CHO}$ on body composition in obese adolescents and

100 examined dietary and physical activity behavior of the whole group during a 2 y follow-

101 up. ${ }^{12}$ In the present study, we compared body characteristics and behavioral patterns in

102 two groups of adolescents according to weight loss maintenance over a 2-year follow-

103 up. In addition, we aimed to evaluate the time when groups differentiated, whether

104 before, during or after treatment.

106 METHODS

108 Subjects

109 This study has been described in details elsewhere. ${ }^{12}$ Briefly, 121 obese adolescents, 110 aged 11 to 16 years, were enrolled in a weight-reducing program lasting 9 months 111 beginning in September 1997. The treatment included controlled diet, physical exercise 112 and psychological support. Of the adolescents included, 99 (29 boys, 70 girls, aged 14.3

$113 \pm 1.2$ years) completed the whole treatment. A total of 72 adolescents were included in 114 the follow-up study 1 and 2 years after the end of treatment. Adolescents lost to follow115 up did not differ significantly in term of sex, age and BMI at the beginning and end of 116 treatment compared to adolescents remaining in the study. The study was approved by 117 the Ethical Committee for the protection of persons participating in biological 118 experimentation (Hospital Paris Saint-Louis) and adolescents and their parents gave 119 written consent to participate. 


\section{Behavioral variables}

\section{Diet}

123 The 72 adolescents considered in this study had a mean stay at the center of 9 months 124 and 12 days. Daily energy intake was limited to $1750 \mathrm{kcal}$ until adolescents had reached 125 a body weight goal determined by the physician. Later on, energy intake increased 126 gradually, in 1-week steps, up to $2200 \mathrm{kcal}$ a day on average (depending on age and 127 sex). This diet was then maintained until the end of treatment. The study was first 128 planned to compare the influence of weight-reducing diets containing different amounts

129 of protein and carbohydrates on body composition in obese adolescents and to examine 130 dietary and physical activity behaviors during follow-up. ${ }^{12}$ One diet $\left(\mathrm{P}^{-}\right)$included $15 \%$ 131 protein and $54 \%$ carbohydrate whereas the other diet $\left(\mathrm{P}^{+}\right)$included $19 \%$ protein and $13250 \%$ carbohydrate. The two diets included a similar amount of fat (31\%). In both cases, 133 energy distribution over the day was as follow: $20 \%$ at breakfast, $31 \%$ at lunch, $16 \%$ at 134 the afternoon snack and 33\% at dinner. Snacking in addition to these four main meals 135 was very occasional in the center. Adolescents were advised to maintain a balanced diet 136 and the same energy level during week-ends and holidays as well as after the end of 137 treatment. Nutrition and in particular, total energy intake, nutrient repartition and daily 138 energy distribution, was evaluated at inclusion in the center and at 1- and 2-year follow139 up at adolescent home. Assessment was carried out by dieticians using the dietary 140 history method. ${ }^{20,21}$

\section{Physical activity and sedentary behavior}

143 In the center, adolescents practiced $7 \mathrm{~h} /$ week of vigorous sports including swimming, 144 tennis, handball, and aerobic, and 7h/week of outdoor activities including walking and 145 playing. They had no possibility to watch television or play video games but were 
146 offered other activities such as reading, acting, and singing. They were advised to

147 maintain physical activity when outside the center, and after the end of treatment.

148 Physical activity (hour/week of regular sport or other activities) and sedentary behavior

149 (hour/week watching television or playing computer) were evaluated at inclusion in the

150 center and at 1- and 2-year follow-up at adolescent home. Assessment was carried out

151 by dieticians using a questionnaire ${ }^{22}$ adapted for French children. ${ }^{23}$

\section{Anthropometry}

154 Adolescent weight was obtained in light clothing (dress or shorts, T-shirt) on an 155 electronic scale to the nearest $100 \mathrm{~g}$ (Testut, France). Height was measured with a wall156 mounted stadiometer (Agencinox, France) and recorded to the nearest $1 \mathrm{~cm}$. During 157 follow-up, weight was measured with an electronic scale to the nearest $100 \mathrm{~g}$ 158 (Terraillon, France) and height with a portable stadiometer to the nearest $1 \mathrm{~cm}$ (Raven

159 Equipment Limited, UK). Triceps skinfold thickness was recorded at the triceps on the 160 right arm with a Harpenden caliper to the nearest $0.2 \mathrm{~mm}$. All body measurements were 161 performed using standard procedures. ${ }^{24,25}$ BMI was computed (weight/height ${ }^{2}$ ). Total 162 upper arm area (TUA) was calculated (midupper arm circumference $2 / 4 \pi$ ) using the 163 Jeliffe and Jellife principle. ${ }^{26}$ Upper arm fat area estimate (UFE) (arm 164 circumference $x$ (triceps skinfold/2) and upper arm muscle area estimate (UME) (TUA 165 UFE) were derived from TUA following the Rolland-Cachera et al. formula. ${ }^{27}$ This $^{2}$ 166 method has been shown to be particularly accurate in the case of obese children and 167 adults $^{27,28}$ compared to the Jelliffe and Jeliffe's method ${ }^{26}$ that overestimates muscle 168 area. Individual BMI growth curves were drawn based on data (length/height and 169 weight) from adolescent's health booklet. Health booklets are given for all newborns in 170 France by the Ministry of Health, and aim at recording anthropometry and health events 
171 occurring during childhood. Age at adiposity rebound corresponding to the nadir in the

172 BMI growth curves ${ }^{29}$ was estimated visually as recommended by Kroke et al. ${ }^{30}$

173

174 Statistics

175 Z-scores were computed for all body characteristics as they allow accounting for the 176 confounding effect of growth. Z-scores of BMI, triceps skinfold thickness, UFE and 177 UME were based on French reference data. ${ }^{27,31}$ LMS values using the Cole et al. 178 method $^{32,33}$ were used for BMI and triceps skinfold thickness. Z-scores of waist 179 circumference and waist/hip ratio were based on data from the ELANCE French 180 cohort. $^{34}$

181 Difference in BMI z-score between the beginning of treatment and the end of follow-up 182 was calculated. Adolescents were categorized in two groups, i.e., "success" vs. "limited 183 or no success", based on this difference. Successful adolescents were defined as those 184 having a BMI z-score reduction above the median ( $\geq 1.24$ standard deviation (SD)), 185 whereas those with limited or no success had a $\mathrm{z}$-score difference below the median 186 (<1.24 SD). Two-tailed Student's t-test was used to determine differences in 187 quantitative physical and behavioral variables between groups. Chi-square test was used 188 for categorical data analysis. Pearson correlations were calculated to evaluate the linear 189 relationship between BMI z-scores values and individual variables. A $P$ value of less 190 than .05 was considered statistically significant. The two groups differing in protein 191 content $\left(\mathrm{P}^{-}\right.$and $\left.\mathrm{P}^{+}\right)$established in the original design were combined in the present 192 analysis since no differences in body measurements were found during treatment and 193 follow-up between the two groups. In addition, an equivalent number of subjects from 194 both diet groups were found in the "success" (18 subjects from each diet group) and in 195 the "limited or no success" (17 subjects from $\mathrm{P}^{-}$vs. 19 subjects from $\mathrm{P}^{+}$) groups. 
196 Statistics were performed using SPSS for Windows (Release 12.0.1., SPSS Inc.,

197 Chicago USA).

199 RESULTS

200 The mean BMI z-score decrease between inclusion and the end of follow-up, was 1.37

$201 \pm 0.92 \mathrm{SD}$ in the whole sample. The reduction was $2.09 \pm 0.68 \mathrm{SD}$ in the successful 202 group and $0.65 \pm 0.43 \mathrm{SD}$ in the group with limited or no success. Changes in $\mathrm{z}$-scores

203 of the different body measurements are shown in Fig. I for both groups.

205 At inclusion and at the end of treatment, groups did not differ significantly for any of 206 the anthropometric characteristics considered, i.e. BMI, triceps skinfold, waist 207 circumference, waist/hip ratio, UFE and UME. In both groups, all characteristics 208 decreased sharply during treatment $(P<.001)$, with the exception of UME, which 209 increased $(P<.05)$. After discharge, differences in anthropometric characteristics

210 between the two groups cleared appeared. In the successful group, BMI, triceps skinfold 211 and UFE slightly increased during the 2-year follow-up while waist circumference 212 remained at the same level. In this group, all these indicators remained lower at the end 213 of follow-up than at inclusion $(P<.001)$. On the other hand, in the group with limited 214 or no success, main changes in these body characteristics appeared in the first year of 215 follow-up and were less marked afterwards. In this group, BMI remained lower at the 216 end of follow-up than at inclusion $(P<.01)$, whereas other indicators did not differ 217 significantly $(P>.05)$. Waist/hip ratio decreased during the first year of follow-up in 218 the successful group, while it stabilized in the group with limited or no success. Values 219 were lower at the end of follow-up than at inclusion for both the successful group 
$220(P<.001)$ and the group with limited or no success $(P<.05)$. In the case of UME,

221 values at 2-year follow-up were not different than at inclusion in both groups $(P>.05)$.

223 Characteristics known to be associated with adolescent obesity are shown in Table I.

224 Adolescents had a mean adiposity rebound occurring early (2.4 years) and even earlier

225 in the case of adolescents with limited or no success. Mothers of successful adolescents

226 tended to have a lower BMI than in the other group. There was no other group

227 difference.

228

229 At admission in the center, adolescent energy intake, nutrient and daily energy 230 distribution, as well as the practice of regular sport were comparable $(P>.05$ for all 231 measurements). In addition, both groups included a similar proportion of adolescents 232 who had followed a restrictive diet prior to the treatment $(P=.63)$. After treatment, and 233 in particular at 2-year follow-up, successful adolescents had lower energy intake than 234 those with limited or no success (Table II). At 2-year follow-up they consumed less 235 energy from protein $(-29.6 \mathrm{kcal})$, from fat $(-151.2 \mathrm{kcal})$, and particularly from 236 carbohydrates $(-234.8 \mathrm{kcal})$, corresponding to a different energy distribution with a 237 higher proportion of protein. In term of daily energy distribution, the successful group 238 had a greater contribution of lunch and breakfast. Adolescents who did not usually have 239 breakfast were 4 to 5 times fewer in the successful group than in the other group, at 2240 and 1-year follow-up, respectively. Successful adolescents snacked significantly less 241 than the others. Adolescents in the two groups did not differ in the practice of regular 242 sport nor of other activities. However, successful adolescents spent less time watching 243 television or using a computer than the other group suggesting a less sedentary 244 behavior. 


\section{DISCUSSION}

249 In the present study, factors associated with long-term weight maintenance after a 9-

250 month weight loss treatment were examined.

252 Adolescents in both groups had a significantly lower BMI at 2-year follow-up than at 253 the beginning of treatment, with about two-thirds of the subjects showing a decrease in 254 BMI greater than $1 \mathrm{SD}$. This persistence of weight loss is encouraging since after treatment, the adolescents had less support and were exposed to numerous factors likely to compromise their ability to maintain their weight loss. It was previously shown by other authors that children and adolescents are able to maintain some of their weight loss after 1 year $^{13}, 5$ years $^{35}$ or 10 years ${ }^{36}$ of follow-up, and do better than adults ${ }^{37}$, although other studies emphasized the considerable relapse after weight reduction programs in children and adolescents. ${ }^{16,38}$

262 Body measurements were not different in the successful group and in the group with 263 limited or no success, neither at the beginning nor at the end of treatment. In addition, at 264 admission in the center, indicators of behaviors i.e. energy intake, nutrient and daily energy distribution, as well as physical activity, were comparable. This result shows that

266 adolescents have the same likelihood to maintain their weight loss after leaving the 267 center independently of their body measurements and behavioral pattern at inclusion 268 and their weight loss during treatment. In contrast, other authors showed that weight loss maintenance was more likely in less obese than in heavier individuals. ${ }^{39}$ 
271 Many authors emphasized the great variation in individual responses to treatment during

272 follow-up. ${ }^{9,40}$ In our study, differences between groups appear when adolescents leave

273 the center and come back in their family environment. Anthropometric differences were

274 clearly visible in the first year after the end of treatment. In the second year, a

275 continuous increase was observed for some body characteristics (e.g. waist

276 circumference), while for others the increase was less marked (e.g. BMI) or even

277 nonexistent (e.g. triceps skinfold thickness). These results suggest that the first year is

278 particularly critical for fat mass regain and that anthropometry at 1-year follow-up is a

279 good predictor of long-term weight loss maintenance. In agreement, Snethen et al. ${ }^{17}$

280 recommended that weight loss programs for children should include an appropriate

281 follow-up for at least 1 year, because it is known that individuals who maintain their

282 weight loss for 1 year are likely to show long-term success. In the present study, waist

283 circumference was a particularly good indicator of weight loss maintenance. This

284 measurement is particularly convenient and recommended when studying obesity

285 because of its relationship with diabetes and other diseases. ${ }^{41}$

287 Adolescents in the group with limited or no success were characterized by a higher 288 energy intake compared to the other group, specifically at 2-year follow-up. They 289 consumed more of all nutrients, but particularly carbohydrates including sucrose. Wing 290 and Hill ${ }^{18}$ showed that weight gainers particularly increased their fat intake compared to 291 weight maintainers. In term of daily energy distribution, in the present study, the 292 successful group tended to eat more at breakfast and lunch than the other group, and to 293 snack less. As a rule, the successful group tended to eat more during the first part of the 
294 day (breakfast and lunch) than the other group. This is consistent with other studies

295 reporting altered daily rhythm in the obese. ${ }^{42-44}$

297 During follow-up, the successful group showed a less sedentary behavior than the other 298 group with significantly less time spent watching television or using computer. 299 However, the practice of sport did not differ significantly between groups. This result 300 shows that it is important to reduce sedentary lifestyle to maintain weight loss. The impact of sedentary behavior on overweight and obesity was shown by numerous

302 authors $^{45-47}$ and a reason proposed was the importance of snacking while watching 303 television. ${ }^{48}$ In our study, time spent in front of the television or computers at 1-year 304 follow-up was significantly correlated with sucrose $(\mathrm{r}=.51, P<.001)$. Restricting access to television or computers and encouraging alternative activities might therefore be a promising approach to help prevent adolescent obesity or relapse after weight loss.

307 However, the importance of exercise should not be underestimated since physical 308 training is associated with beneficial changes in fat and lean body mass. ${ }^{22,49}$

309 Incidentally, both groups showed a decrease of lean body mass after leaving the center,

310 probably due to a decrease in physical activity.

312 It is clearly established that age at adiposity rebound is associated with obesity later in

313 life and that it occurs earlier in the obese (around 3 years) than in normal subjects

314 (around 6 years). ${ }^{50}$ Mean age at adiposity rebound in the present study was 2.4 years

315 and occurred even earlier in the group with limited or no success. In addition, mothers 316 of adolescents in the successful group tended to have a lower BMI than those in the 317 other group. It is known that children with overweight parents have a greater risk of 318 becoming overweight ${ }^{4,17,51,52}$ due to genetic and/or environment. An early adiposity 
319 rebound and high maternal BMI can reflect the influence of early determinants. ${ }^{50-52}$ The

320 influence of early life determinants in weight loss maintenance after treatment should

321 therefore not be underestimated. Besides, mother weight can reflect family habits. Thus,

322 family therapy and involvement could be used as improving the support for the child by

323 the family. ${ }^{53,54}$

324

325 This type of intervention lasting a few months can present some disadvantages. 326 Adolescents are supervised over a long period and it can be difficult for them to follow

327 an adequate diet without control, after leaving the center. On the other hand, the long

328 period of treatment is likely to favor an imprinting of positive behaviors. The long

329 follow-up in this study presents the advantage to give a good indication of the long term

330 success of treatment, although the drop-out rate may limit the interpretation of the

331 results. Finally, it must be noted that there is no consensus on what method should be

332 used to evaluate success of weight loss maintenance. Success or failure is likely to differ

333 according to the method selected. We defined success of weight loss maintenance using

334 z-score differences between the end of follow-up and the beginning of the study. This

335 method is now increasingly used for this type of evaluation. ${ }^{10,15}$

\section{Conclusion}

338 This study identifies factors related to long-term outcome of weight loss treatment in

339 obese adolescents. Neither behavior at inclusion nor body measurements before and

340 during treatment were associated with weight loss maintenance over a 2-year follow-up.

341 Rather, the difficulty in maintaining weight loss seemed to be related to the difficulty in

342 making permanent changes in dietary and sedentary behaviors after treatment. Some

343 adolescents were able to make life-style changes following advice received during 
344 treatment, while others were not. Weight loss maintenance was also related to the

345 child's age at adiposity rebound and mother's BMI, highlighting the importance of early

346 life determinants as well as the importance of the family environment. The fact that, in

347 the present study, a large proportion of adolescents were able to maintain their weight

348 loss is encouraging. More research is required to identify the factors associated with

349 treatment outcome in order to improve long-term maintenance of weight loss in obese

350 adolescents.

351

352

353

354

355

356 References

357 
358

359

360 
References

364

365 1. Dehghan M, Akhtar-Danesh N, Merchant AT. Childhood obesity, prevalence and $366 \quad$ prevention. Nutr J 2005; 4:24.

2. Dietz WH. Health consequences of obesity in youth: childhood predictors of adult disease. Pediatrics 1998; 101:518-25.

3. Power C, Lake JK, Cole TJ. Measurement and long-term health risks of child and adolescent fatness. Int J Obes Relat Metab Disord 1997; 21:507-26.

4. Whitaker RC, Wright JA, Pepe MS, Seidel KD, Dietz WH. Predicting obesity in young adulthood from childhood and parental obesity. N Engl J Med 1997; 337:869-73.

5. Must A, Jacques PF, Dallal GE, Bajema CJ, Dietz WH. Long-term morbidity and mortality of overweight adolescents. A follow-up of the Harvard Growth Study of 1922 to 1935. N Engl J Med 1992; 327:1350-5.

6. Cooper C, Sarvey S, Collier D, Willson C, Green I, Pories ML et al. For comparison: experience with a children's obesity camp. Surg Obes Relat Dis 2006; multidisciplinary weight loss intervention on body composition in obese adolescents. Int J Obes Relat Metab Disord 2004; 28:290-9. 
8. Figueroa-Colon R, von Almen TK, Franklin FA, Schuftan C, Suskind RM. Comparison of two hypocaloric diets in obese children. Am J Dis Child 1993;

10. Gately PJ, Cooke CB, Barth JH, Bewick BM, Radley D, Hill AJ. Children's

12. Rolland-Cachera MF, Thibault H, Souberbielle JC, Soulie D, Carbonel P,

13. Walker LL, Gately PJ, Bewick BM, Hill AJ. Children's weight-loss camps:

14. Braet C. Patient characteristics as predictors of weight loss after an obesity treatment for children. Obesity (Silver Spring) 2006; 14:148-55. 
405 15. Germann JN, Kirschenbaum DS, Rich BH, O'Koon JC. Long-term evaluation of 406 multi-disciplinary treatment of morbid obesity in low-income minority 407 adolescents: La Rabida Children's Hospital's FitMatters program. J Adolesc $408 \quad$ Health 2006; 39:553-61.

409 16. Gibson LJ, Peto J, Warren JM, dos SS, I. Lack of evidence on diets for obesity for $410 \quad$ children: a systematic review. Int J Epidemiol 2006; 35:1544-52.

411 17. Snethen JA, Broome ME, Cashin SE. Effective weight loss for overweight 412 children: a meta-analysis of intervention studies. J Pediatr Nurs 2006; 21:45-56.

413 18. Wing RR, Hill JO. Successful weight loss maintenance. Annu Rev Nutr 2001; $414 \quad 21: 323-41$

415 19. Lohman TG, Going SB. Body composition assessment for development of an 416 international growth standard for preadolescent and adolescent children. Food $417 \quad$ Nutr Bull 2006; 27:S314-S325.

418 20. Burke BS. The dietary history as a tool research. J Am Diet Assoc 1947; 23:10414196.

420 21. Deheeger M, Bellisle F, Rolland-Cachera MF. The French longitudinal study of 421 growth and nutrition: data in adolescent males and females. J Hum Nutr Diet 422 $2002 ; 15: 429-38$.

22. Kriska AM, Knowler WC, LaPorte RE, Drash AL, Wing RR, Blair SN et al. 424 Development of questionnaire to examine relationship of physical activity and 425 diabetes in Pima Indians. Diabetes Care 1990; 13:401-11. 
23. Deheeger M, Rolland-Cachera MF, Fontvieille AM. Physical activity and body composition in 10 year old French children: linkages with nutritional intake? Int J Obes Relat Metab Disord 1997; 21:372-9.

24. Physical status: the use and interpretation of anthropometry. Report of a WHO Expert Committee. World Health Organ Tech Rep Ser 1995; 854:1-452.

25. Lohman TG, Roche AF, Martorell R. Anthropometric standardization reference manual. Human kinetics; 1988.

26. Jelliffe EFP, Jelliffe DB. The arm circumference as a public health index of protein-calorie malnutrition of early childhood. J Trop Pediatr 1969; 32:1527-30.

27. Rolland-Cachera MF, Brambilla P, Manzoni P, Akrout M, Sironi S, Del Maschio A et al. Body composition assessed on the basis of arm circumference and triceps skinfold thickness: a new index validated in children by magnetic resonance imaging. Am J Clin Nutr 1997; 65:1709-13.

28. Rolland-Cachera MF, Brambilla P. Reference body composition and anthropometry. Int J Obes (Lond) 2005; 29:1010.

29. Rolland-Cachera MF, Deheeger M, Bellisle F, Sempe M, Guilloud-Bataille M, Patois E. Adiposity rebound in children: a simple indicator for predicting obesity. Am J Clin Nutr 1984; 39:129-35.

30. Kroke A, Hahn S, Buyken AE, Liese AD. A comparative evaluation of two different approaches to estimating age at adiposity rebound. Int $\mathbf{J}$ Obes (Lond) 2006; 30:261-6. 
31. Sempé M, Pédron G, Roy-Pernot MP. Auxologie: méthode et séquences. Théraplix; 1979.

32. Cole TJ. The LMS method for constructing normalized growth standards. Eur J Clin Nutr 1990; 44:45-60.

33. Rolland-Cachera MF, Cole TJ, Sempe M, Tichet J, Rossignol C, Charraud A. Body Mass Index variations: centiles from birth to 87 years. Eur J Clin Nutr 1991;

34. Deheeger M, Rolland-Cachera MF. [Longitudinal study of anthropometric

35. Knip M, Nuutinen O. Long-term effects of weight reduction on serum lipids and

36. Epstein LH, Valoski A, Wing RR, McCurley J. Ten-year follow-up of behavioral, family-based treatment for obese children. JAMA 1990; 264:2519-23.

37. Epstein LH, Valoski AM, Kalarchian MA, McCurley J. Do children lose and maintain weight easier than adults: a comparison of child and parent weight changes from six months to ten years. Obes Res 1995; 3:411-7.

38. Epstein LH, Myers MD, Raynor HA, Saelens BE. Treatment of pediatric obesity. Pediatrics 1998; 101:554-70.

39. Ogden CL, Carroll MD, Curtin LR, McDowell MA, Tabak CJ, Flegal KM. Prevalence of overweight and obesity in the United States, 1999-2004. JAMA 2006; 295:1549-55. 
40. Nederkoorn C, Jansen E, Mulkens S, Jansen A. Impulsivity predicts treatment outcome in obese children. Behav Res Ther 2007; 45:1071-5.

41. McCarthy HD. Body fat measurements in children as predictors for the metabolic syndrome: focus on waist circumference. Proc Nutr Soc 2006; 65:385-92.

42. Bellisle F, Rolland-Cachera MF, Deheeger M, Guilloud-Bataille M. Obesity and 474

44. Stunkard AJ, Grace WJ, Wolff HG. The night-eating syndrome; a pattern of food intake among certain obese patients. Am J Med 1955; 19:78-86.

45. Berkey CS, Rockett HR, Field AE, Gillman MW, Frazier AL, Camargo CA, Jr. et al. Activity, dietary intake, and weight changes in a longitudinal study of preadolescent and adolescent boys and girls. Pediatrics 2000; 105:E56.

46. Lioret S, Maire B, Volatier JL, Charles MA. Child overweight in France and its relationship with physical activity, sedentary behaviour and socioeconomic status. Eur J Clin Nutr 2007; 61:509-16.

47. Tremblay MS, Willms JD. Is the Canadian childhood obesity epidemic related to physical inactivity? Int J Obes Relat Metab Disord 2003; 27:1100-5.

48. Robinson TN. Reducing children's television viewing to prevent obesity: a randomized controlled trial. JAMA 1999; 282:1561-7. 
49. Watts K, Jones TW, Davis EA, Green D. Exercise training in obese children and adolescents: current concepts. Sports Med 2005; 35:375-92.

50. Rolland-Cachera MF, Deheeger M, Maillot M, Bellisle F. Early adiposity rebound: causes and consequences for obesity in children and adults. Int $\mathrm{J}$ Obes (Lond) 2006; 30 Suppl 4:S11-S17.

51. Berkowitz RI, Stallings VA, Maislin G, Stunkard AJ. Growth of children at high risk of obesity during the first $6 \mathrm{y}$ of life: implications for prevention. Am J Clin Nutr 2005; 81:140-6.

52. Reilly JJ, Armstrong J, Dorosty AR, Emmett PM, Ness A, Rogers I et al. Early life risk factors for obesity in childhood: cohort study. BMJ 2005; 330:1357.

53. Epstein LH, Wing RR, Koeske R, Andrasik F, Ossip DJ. Child and parent weight loss in family-based behavior modification programs. J Consult Clin Psychol $1981 ; 49: 674-85$.

54. Flodmark CE, Lissau I, Moreno LA, Pietrobelli A, Widhalm K. New insights into the field of children and adolescents' obesity: the European perspective. Int J Obes Relat Metab Disord 2004; 28:1189-96. 


\section{$509 \quad$ Fig. I}

510 Changes in body characteristics z-scores in the successful group (-) and in the group

511 with limited or no success (---) at 4 examination points: inclusion $\left(\mathrm{T}_{0}\right)$, end of treatment

$512\left(\mathrm{~T}_{\text {end }}\right), 1\left(\mathrm{~F}_{1 \mathrm{y}}\right)$ and 2-year $\left(\mathrm{F}_{2 \mathrm{y}}\right)$ follow-up after treatment. Differences between groups

513 are shown: $n s$ non-significant, $* P<.05$, ** $P<.01$, *** $P<.001$.

514 BMI: body mass index, UFE: upper arm fat area estimate, UME: upper arm muscle area 515 estimate. 